\title{
Plastic Deformation of Metal Tubes Subjected to Lateral Blast Loads
}

\author{
Kejian Song, ${ }^{1}$ Yuan Long, ${ }^{1}$ Chong Ji, ${ }^{1,2}$ and Fuyin Gao ${ }^{1}$ \\ ${ }^{1}$ College of Field Engineering, PLA University of Science and Technology, Nanjing 210007, China \\ ${ }^{2}$ National Key Laboratory of Explosion Science and Technology, Beijing Institute of Technology, Beijing 10081, China
}

Correspondence should be addressed to Chong Ji; blastingcaptain@163.com

Received 20 February 2014; Revised 8 November 2014; Accepted 9 November 2014; Published 20 November 2014

Academic Editor: Igor Andrianov

Copyright (c) 2014 Kejian Song et al. This is an open access article distributed under the Creative Commons Attribution License, which permits unrestricted use, distribution, and reproduction in any medium, provided the original work is properly cited.

When subjected to the dynamic load, the behavior of the structures is complex and makes it difficult to describe the process of the deformation. In the paper, an analytical model is presented to analyze the plastic deformation of the steel circular tubes. The aim of the research is to calculate the deflection and the deformation angle of the tubes. A series of assumptions are made to achieve the objective. During the research, we build a mathematical model for simply supported thin-walled metal tubes with finite length. At a specified distance above the tube, a TNT charge explodes and generates a plastic shock wave. The wave can be seen as uniformly distributed over the upper semicircle of the cross-section. The simplified Tresca yield domain can be used to describe the plastic flow of the circular tube. The yield domain together with the plastic flow law and other assumptions can finally lead to the solving of the deflection. In the end, tubes with different dimensions subjected to blast wave induced by the TNT charge are observed in experiments. Comparison shows that the numerical results agree well with experiment observations.

\section{Introduction}

Pipeline systems are the main elements of many types of engineering structures, such as aerospace, marine, petrochemical, nuclear, and power generation. Suffering impact or blast loads, the structures will undergo large deflection or even damage. Due to the increased security needs and the occurrence of accidental or intentional explosions, the subjects of structures suffering transverse blast load are of interest all over the world [1-6].

In most engineer applications, structural elements can be geometrically classified as being beams or plates. As for tubes, they can be classified as being hollow beams or thin wall cylindrical shells. The subject plays an important role in the industrial systems, so there have been many experimental and analytical investigations focus on the structures behaviors when subjected to transverse blast load. The previous investigations are mostly on beams, including blast tests on solid steel beams done by Humphreys [7] and Jones et al. [8]. Symonds and Jones [9] also did experimental research on fully clamped beams. The analytical investigations of rigidplastic beams subjected to transverse impulsive loads were done by Lee and Symonds [10], Symonds [11], and Jones [12]. The methods they used are generally based on the exact maximum normal stress bending-membrane yield curve shown in Figure 1, which can be simplified using the approximate square yield curves also shown in Figure 1. The square yield curve can provide reasonable bounds to the exact solution and good agreement with tests in references $[8,9,13]$. The above experimental and analytical investigations are mainly on the behaviors of solid beam section, while the hollow sections provide an additional complication for the localized cross-section distortions in addition to the beam-bending deflections. The research on the steel circular hollow beams mostly focuses on the quasistatic transverse loads, which result in both local indentations and global beam bending [14-16]. However, only a small number of studies on steel hollow section beam subjected to local transverse impact load can be found. Jones et al. reported an extensive series of experiments on clamped circular tubes under transverse impact loads at different points along the span [17]. Analytical studies by Jones et al. provided rigid-plastic solutions using exact parabolic interaction curves of the locally deformed sections. Some other papers also study the effects of internal pressure 


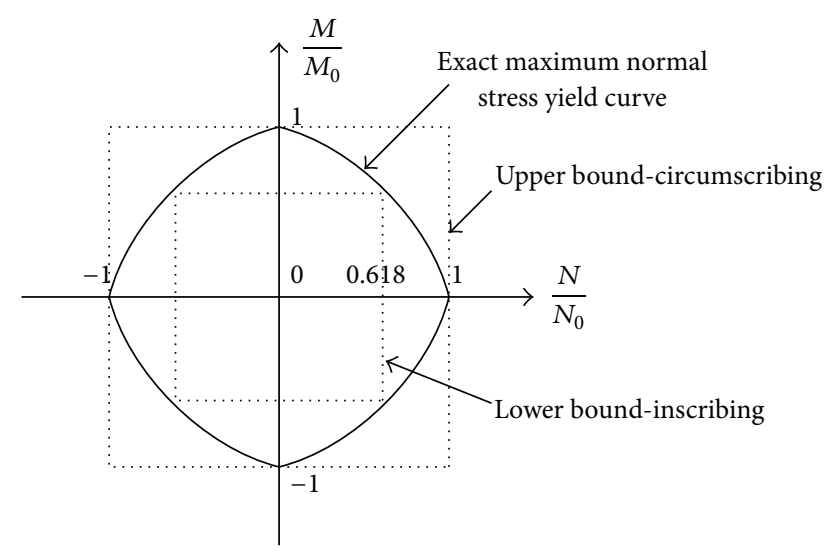

FIGURE 1: Exact and approximate (square) moment axial yield curves.

on the transverse impact response of circular hollow section beams $[18,19]$. There is a very strong tendency that the final expressions of the dynamic plastic deformation should be presented in a dimensionless form [20, 21]. In Zhao's paper, he suggested a dimensionless number, which is named "Response Number Rn" and widely used for the characterizing of the dynamic plastic deformation of various structures [21].

From the above discussion we can see that most researches idealize the material behavior as being elasticperfectly plastic or rigid-perfectly plastic. Such a simplification permits the study of the main characteristics of structures with relative simplicity and without great loss of accuracy. In fact, the dynamic structural response can be satisfactorily predicted by a rigid-plastic model [22], in which the governing equations of the structure can be greatly simplified by neglecting elastic effects on the plastic deformation.

As is mentioned in Yakupov's paper [23], suffering external loads, lots of the pipelines used in the underground oil traveling industry or the offshore industry will experience local deformation. Yakupov made a series of researches on the local plastic deformations of cylindrical shell under the action of the explosive. Based on Yakupov's theory, this paper introduces an analytical method to study the dynamic plastic deformation of metal tubes subjected to lateral blast loads and also reveal the relationships between the structures and the shock waves. During the research, we set up a calculation model to study the dynamic response of steel tubes shown in Figure 2. The thin-walled tubes with finite length are simply supported at the two ends. At a specified distance above the tube, a TNT charge explodes and generates a plastic shock wave. The shock wave can lead to the local plastic deformation of the tube as shown in Figure 3. Based on the different intensity of the wave, we can divide the plastic deformation progress into two modes: Mechanism I and Mechanism II. According to the plastic dynamic theories, we can assume the tube material to be ideally rigid-plastic and use the piecewise-linear Tresca yield condition to simulate the plasticity condition of the tubes. The yield conditions together

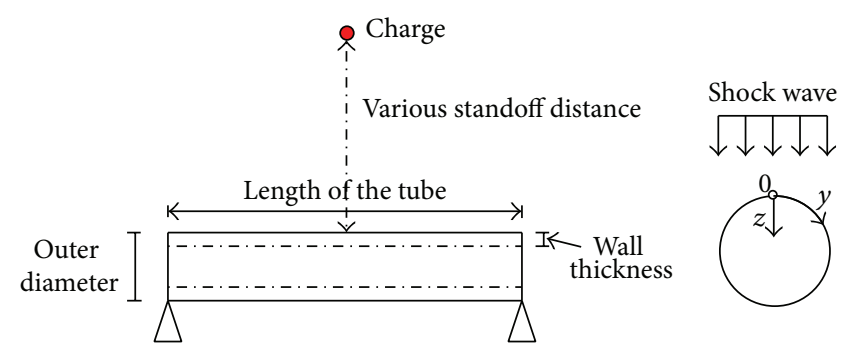

Figure 2: Analysis model and the coordinate system.

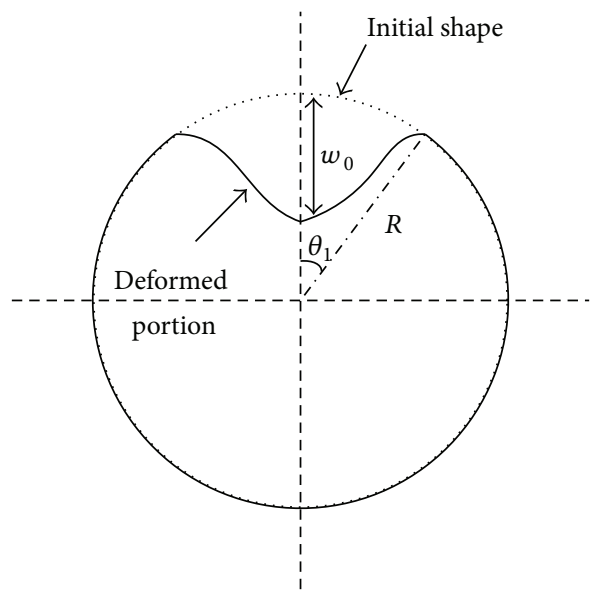

FIgURE 3: Schematic representation of the local deformation.

with the plastic flow law and initiation conditions can lead to the final plastic deformation of the thin-walled tubes.

\section{Theoretical Analysis Model}

2.1. Shock Wave Load. The theoretical analysis model is shown in Figure 2. The shape of the explosive charge is assumed to be cuboid, so the shock wave can be seen as planar waves at the middle spot of the tube. The shock wave produced by the detonation causes the air to move. When the wave reaches the surface of the tube, the interaction between the moving air and the tube impedes the air velocity and causes a significant increase in the load on the tube surface. The pressure on the surface rises very quickly to the peak reflected pressure, instead of the incident peak pressure. Then the reflected pressure decays to zero within $t_{0}$. The typical pressure-time history curve is shown in Figure 4. In order to simplify the calculation, we use the decaying shapes shown in Figure 4(b).

As the pressure only acts on the upper part of the circular section, so we can use the "isolated element principle" [23] and define the wave pressure in the following form:

$$
P(t)= \begin{cases}P_{1}\left(1-\frac{t}{t_{0}}\right) \cos \theta, & -\frac{\pi}{2} \leq \theta \leq \frac{\pi}{2} \\ 0, & -\frac{\pi}{2} \leq \theta \leq \frac{\pi}{2}\end{cases}
$$




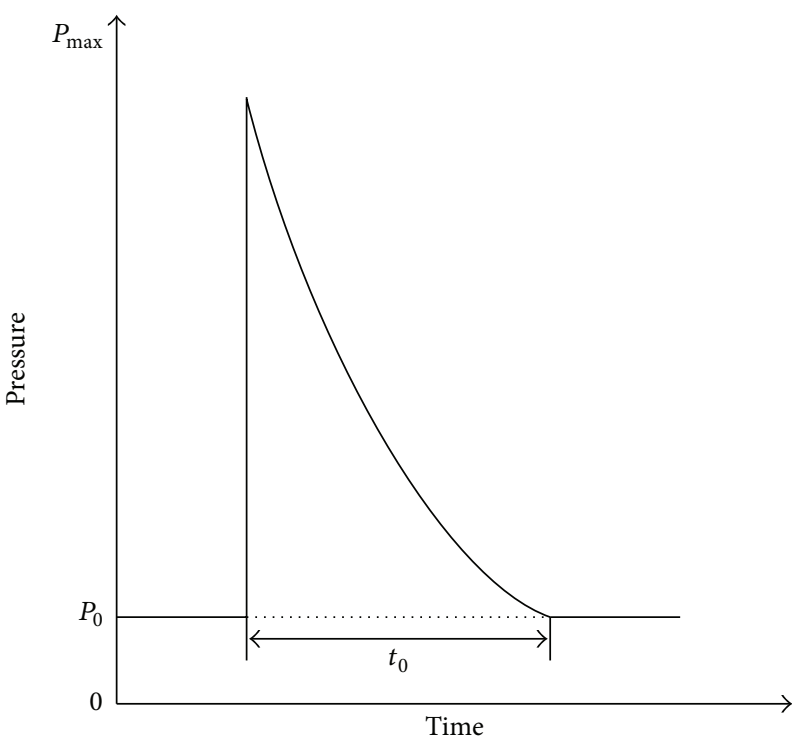

(a)

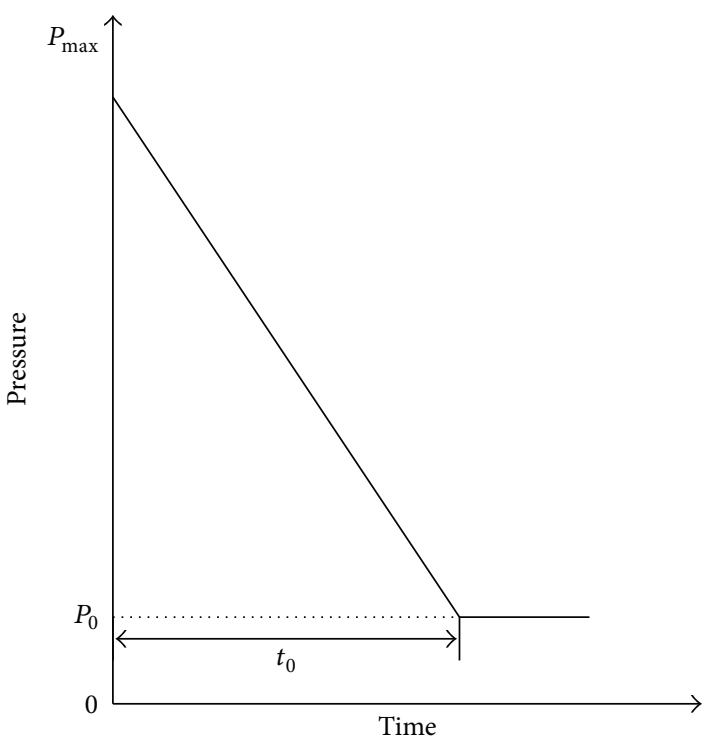

(b)

FIgURE 4: Different decaying shapes of the shock wave.

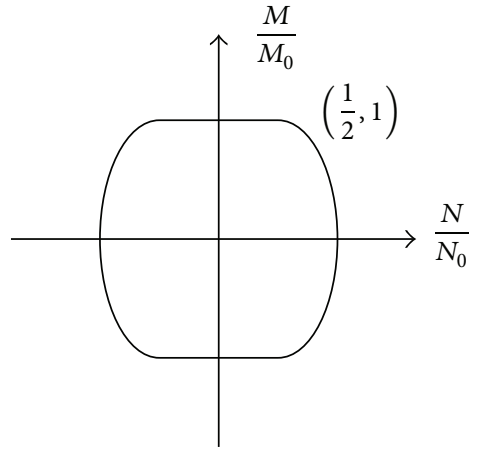

(a) Uniform thickness

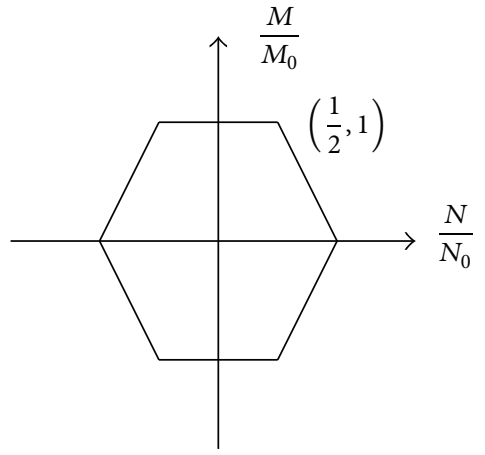

(b) Ideal sandwich

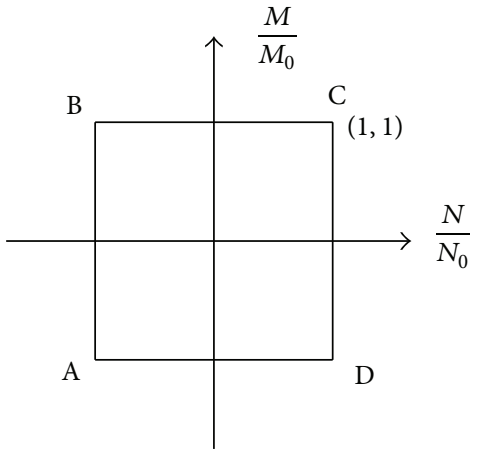

(c) Simplest approximation

FIGURE 5: Yield domains.

where $P_{1}$ is the peak pressure of the reflected wave and $P_{1}=$ $P_{0}(1+\sqrt{n}) ; n$ is the compression exponent; $t_{0}$ is the period over which the pressure acts; and $\theta$ is the angular coordinate.

2.2. Governing Equation. The dynamic behavior of the thinwalled cylindrical shell can be expressed in the following form [22]:

$$
\begin{gathered}
\frac{\partial^{2} M_{y}}{\partial y^{2}}+\left(\left(\frac{1}{R}\right)+\frac{\partial^{2} \omega}{\partial y^{2}}\right) N_{y}+P-\rho H \frac{\partial^{2} \omega}{\partial t^{2}}=0 \\
\frac{\partial T}{\partial y}=\frac{\partial N_{y}}{\partial y}=0
\end{gathered}
$$

where $M_{y}$ is the bending moment in the peripheral direction; $T$ and $N_{y}$ are the tangent and normal stresses in the mean surface; $R$ and $H$ are the radius and thickness of the tube; $\rho$ is the density of the material; $P$ is the pressure defined in (1).
The prime denotes differentiation with respect to $y$ and the dot with respect to $t$.

2.3. Yield Condition. According to Hodge and Norman's theories, the phenomena which actually take place under a dynamic loading will be complex, but certain simplifications may be made in order to get the satisfying result. The present paper is concerned with a load which is greater than the static collapse load so that the elastic strains, both static and dynamic, may reasonably be neglected. For a perfectly plastic material, the reduced stress resultants must satisfy certain inequalities which depend upon the yield condition and the cross-section of the tube. This may be expressed in geometrical terms by stating that the stress point must lie within a certain bounded domain called the yield domain. For the particular case of Tresca's (maximum shearing stress) yield condition, Drucker has found the yield domain of Figure 5(a) for a uniform section and Hodge has found the curve of Figure 5(b) for an ideal sandwich section. In the analysis to 
TABLE 1: Expressions for the generalized stresses and deformation rates.

\begin{tabular}{lcccc}
\hline $\begin{array}{l}\text { Plastic } \\
\text { mode }\end{array}$ & $N / N_{0}$ & $M / M_{0}$ & \multicolumn{2}{c}{ Vector deformation rate } \\
\hline $\mathrm{AD}$ & $-1 \leq N / N_{0} \leq 1$ & -1 & $\dot{w}=0$ & $\dot{w}^{\prime \prime} \geq 0$ \\
$\mathrm{~A}$ & -1 & -1 & $\dot{w} \geq 0$ & $\dot{w}^{\prime \prime} \geq 0$ \\
$\mathrm{AB}$ & -1 & $-1 \leq M / M_{0} \leq 1$ & $\dot{w} \geq 0$ & $\dot{w}^{\prime \prime}=0$ \\
$\mathrm{~B}$ & -1 & 1 & $\dot{w} \geq 0$ & $\dot{w}^{\prime \prime} \leq 0$ \\
\hline
\end{tabular}

follow, a simplified yield domain as shown in Figure 5(c) will be considered. The simplified yield condition has been used in many research papers.

For a perfectly plastic material the stress profile must lie in or on the yield domain. Points of the tube where the stress profile lies within the yield domain must remain rigid, while at a boundary point a certain strain rate vector must be normal to the boundary. From Hodge we can see in this paper only the sides $\mathrm{AD}$ and $\mathrm{AB}$ and the vertices $\mathrm{A}$ and $\mathrm{B}$ of the yield domain are appropriate, and these will be denoted by plastic regime $\mathrm{AD}$, plastic regime $\mathrm{A}$, and so forth. The resulting stresses and strain-rates are listed in Table 1, together with the equations and inequalities which derive from them.

\section{Mechanism of Local Plastic Deformation}

3.1. Mechanism I. For rigid-plastic structures undergoing large displacements, the rate of external work and the rate of internal energy dissipation are fully defined by prescribing suitable velocity and displacement fields. The accuracy of the approximate solutions depended on the right choice of the velocity and displacement fields. During this mechanism, when the incident wave pressure is greater than the static collapse pressure of the tube, there appear three plastic joints at the points $\theta=0, \pm \theta_{1}$ (Figure 6). The middle plastic joint is moving while the other two are static ones.

From the above discussion we know that the segments between the two static joints are in a plastic state $\mathrm{AD}$. The flow law corresponding to this state can be written in the form:

$$
\dot{\varepsilon}_{y}: \dot{\kappa}_{y}=-1: 0 \text {, }
$$

where $\dot{\varepsilon}_{y}$ and $\dot{\kappa}_{y}$ are generalized deformation velocities, corresponding to generalized stress $N_{y}$ and $M_{y}$. From Table 1 we can acquire the following equation:

$$
\dot{\kappa}_{y}=\dot{\omega}^{\prime \prime}=0 .
$$

Thus the flow law which is a solution of the above equation can be defined as (Figure 5)

$$
\dot{\omega}_{0}=c_{1} y+c_{2},
$$

where $c_{1}$ and $c_{2}$ are constants and satisfying the conditions:

$$
\begin{aligned}
& \dot{\omega}_{0}=\dot{\omega}_{1} \quad(y=0), \\
& \dot{\omega}_{0}=0 \quad\left(y=y_{1}\right) .
\end{aligned}
$$

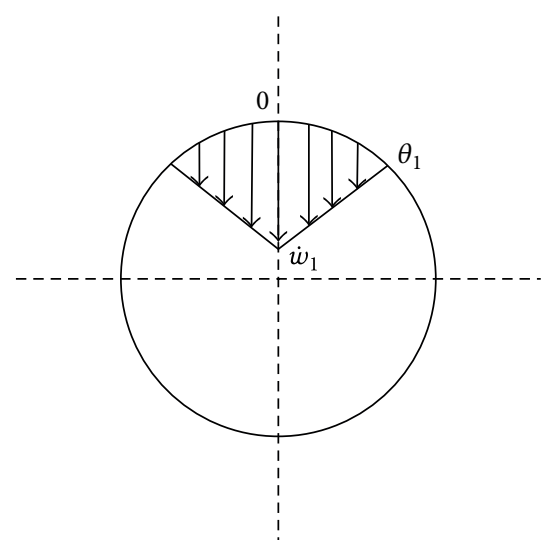

FIGURE 6: Velocity profile of Mechanism I.

Applying the initial conditions to the velocity equation, we can acquire the following velocity equations:

$$
\begin{array}{ll}
\dot{\omega}_{0}=\dot{\omega}_{1}\left(1-\frac{y}{y_{1}}\right) & \left(0 \leq y \leq y_{1}\right), \\
\dot{\omega}_{0}=\dot{\omega}_{1}\left(1+\frac{y}{y_{1}}\right) & \left(-y_{1} \leq y \leq 0\right) .
\end{array}
$$

From the above discussion and using the stress field and flow law, we can transform (2) to the following form:

$$
\frac{\partial^{2} M_{y}}{\partial y^{2}}-\frac{N_{0}}{R}+P-m_{0} \frac{\partial^{2} \omega}{\partial t^{2}}=0 .
$$

The solution of (8) must also satisfy the boundary conditions:

$$
\begin{aligned}
& M(0, t)=M_{0}, \\
& M^{\prime}(0, t)=0, \\
& M\left( \pm \theta_{1}, t\right)=-M_{0}, \\
& M^{\prime}\left( \pm \theta_{1}, t\right)=0 .
\end{aligned}
$$

If we denote by $M_{1}$ the bending moment of the region $0 \leq y \leq y_{1}$, substituting in (8) the equation (1) and the first equation of (7) and satisfying the first two equations of (9), we can get the following equation:

$$
\begin{aligned}
M_{1}= & \left(\frac{N_{0}}{R}+m_{0} \ddot{\omega}_{1}\right) \frac{y^{2}}{2}-P_{1}\left(1-\frac{t}{t_{0}}\right)(1-\cos \theta) \\
& -m_{0} \ddot{\omega}_{1} \frac{y^{3}}{6 y_{1}}+M_{0} .
\end{aligned}
$$

Applying the last two equations of (9) to (10) and transform $y$ to the angular coordinate, we get

$$
\begin{aligned}
& \frac{m_{0} \theta_{1}^{2}}{3} \ddot{\omega}_{1}=P_{1}\left(1-\frac{t}{t_{0}}\right)\left(1-\cos \theta_{1}\right)-\frac{2 M_{0}}{R^{2}}-\frac{N_{0} \theta_{1}^{2}}{2 R}, \\
& \frac{m_{0} \theta_{1}}{2} \ddot{\omega}_{1}=P_{1}\left(1-\frac{t}{t_{0}}\right) \sin \theta_{1}-\frac{N_{0} \theta_{1}}{R} .
\end{aligned}
$$




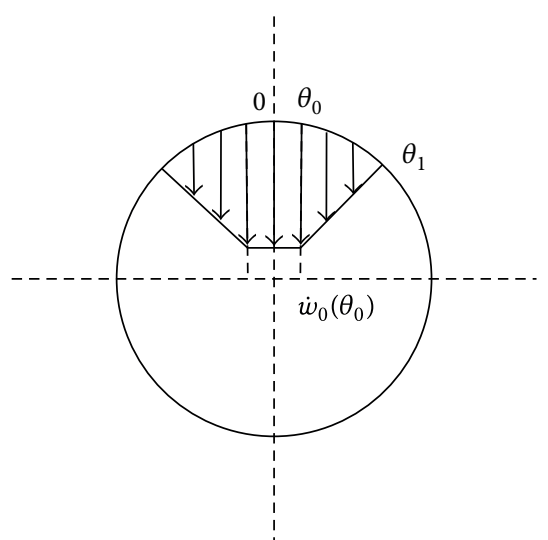

Figure 7: Velocity profile of Mechanism II.

If we set $\ddot{\omega}_{1}=t=0$ in (11), we can get the expressions for the limiting static pressure in the following forms:

$$
\begin{aligned}
& P_{s}=\frac{N_{0} R \theta_{s}^{2}+4 M_{0}}{2 R^{2}\left(1-\cos \theta_{s}\right)}, \\
& P_{s}=\frac{N_{0} \theta_{s}}{R \sin \theta_{s}} .
\end{aligned}
$$

From (11) we can also get the expression for the coordinate $\theta_{1}$ as a function of wave pressure at the time of reflection:

$$
P_{1}=\frac{12 M_{0}-N_{0} R \theta_{1}^{2}}{2 R^{2}\left[3\left(1-\cos \theta_{s}\right)-2 \theta_{1} \sin \theta_{1}\right]} .
$$

As (10) must obey the yield condition: $M_{1}^{\prime \prime}(0, t) \leq 0$, $M_{1}^{\prime \prime}\left( \pm \theta_{1}, t\right) \geq 0$, we can acquire the following conditions for $P_{0}$ of Mechanism I:

$$
P_{1} \leq \frac{N_{0} \theta_{1}}{R\left(2 \sin \theta_{1}-\theta_{1}\right)}, \quad P_{1} \leq \frac{N_{0}}{R \cos \theta_{1}} .
$$

3.2. Mechanism II. When the shock wave pressure is much greater than that in Mechanism I, there appear four plastic joints at the points $\theta= \pm \theta_{0}, \pm \theta_{1}$ (Figure 7). During this mechanism, region I $\left(-\theta_{0} \leq \theta \leq \theta_{0}\right)$ is in a plastic state $\mathrm{A}$, while region II is in a plastic state $\mathrm{AD}$ (Figure 5(c)).

According to the plastic flow law, we can get velocity field in the following form (Figure 6):

$$
\begin{aligned}
& \dot{w}=\dot{w}_{0} \quad\left(0 \leq \theta \leq \theta_{0}\right), \\
& \dot{w}=\dot{w}_{0}\left(\frac{y-R \theta_{1}}{R\left(\theta_{0}-\theta_{1}\right)}\right) \quad\left(\theta_{0} \leq \theta \leq \theta_{1}\right) .
\end{aligned}
$$

Based on Jones's theory, we can get the equation of motion for region I:

$$
m_{0} \ddot{w}_{0}=P_{1}\left(1-\frac{t}{t_{0}}\right) \cos \theta-\frac{N_{0}}{R} .
$$

As for region II, analysis is analogous to that in Mechanism I. We can substitute in (8) the second expression of (15). The solution must satisfy the following conditions:

$$
\begin{aligned}
& M\left(\theta_{0}, t\right)=M_{0}, \\
& M\left(\theta_{1}, t\right)=-M_{0}, \\
& M^{\prime}\left(\theta_{0}, t\right)=0, \\
& M^{\prime}\left(\theta_{1}, t\right)=0 .
\end{aligned}
$$

Applying the above conditions, we can get

$$
\begin{aligned}
& \frac{m_{0} f_{1}}{3}\left(f_{1} \ddot{w}_{0}+\dot{\theta}_{0} \dot{w}_{0}\right)=P_{1}\left(1-\frac{t}{t_{0}}\right) f_{2}-\frac{N_{0}}{2 R} f_{1}^{2}-\frac{2 M_{0}}{R^{2}}, \\
& \frac{m_{0}}{2}\left(f_{1} \ddot{w}_{0}+\dot{\theta}_{0} \dot{w}_{0}\right)=P_{1}\left(1-\frac{t}{t_{0}}\right) f_{3}-\frac{N_{0}}{R} f_{1},
\end{aligned}
$$

where $f_{1}=\theta_{1}-\theta_{0} ; f_{2}=\cos \theta_{0}-\cos \theta_{1}-\left(\theta_{1}-\theta_{0}\right) \sin \theta_{0}$; $f_{3}=\sin \theta_{1}-\sin \theta_{0}$.

The expression for the coordinate $\theta_{0}$ as a function of wave pressure has the form:

$$
P_{1}=\frac{\left(N_{0} / R\right) f_{1}^{2}-12 M_{0} / R^{2}}{4 f_{1} f_{3}-6 f_{2}} .
$$

From the yield condition: $M_{2}^{\prime \prime}\left(\theta_{0}, t\right) \leq 0, M_{2}^{\prime \prime}\left(\theta_{1}, t\right) \geq 0$, we can acquire the following conditions for $P_{0}$ of Mechanism II:

$$
P_{1} \leq \frac{N_{0} R f_{1}^{2}+12 M_{0}}{2 R^{2}\left(3 f_{2}-f_{1}^{2} \cos \theta_{0}\right)}, \quad P_{1} \leq \frac{N_{0}}{R \cos \theta_{1}} .
$$

In Mechanism II, the motion of the tube can be divided into three stages. The first is the drive stage. During the first stage, the plastic joint $\theta_{0}$ remains static. At the end of the first stage the velocity reaches its highest value and the acceleration velocity decays to zero. In the second stage, the plastic joint $\theta_{0}$ begins to move from $\theta_{0}$ to 0 . The velocity of the moving joint can be calculated from (16). Analysis of the third stage is analogous to that in Mechanism I. At the end of the third stage, the velocity decays to zero.

\section{Numerical Examples}

Consider a steel circular tube with the dimensions $R=$ $50 \mathrm{~mm}$ and $H=2.75 \mathrm{~mm}$. The yield point of the material $\sigma_{s}=$ $320 \mathrm{~N} / \mathrm{mm}^{2}$, and the density of the tube $\rho=7800 \mathrm{~kg} / \mathrm{m}^{3}$. The duration of the load $t_{0}$, as in Chen et al. [24], is taken as $1.5 \mathrm{~ms}$. From (12) we can get the value of angular coordinate $\theta_{s}=$ 0.8832 . Meanwhile from the same equation we can acquire different values of $\theta_{s}$ depending on different values of $H / R$, as shown in Figure 8.

From (12) we can get the limiting static pressure for Mechanism I, $P_{s}=23.2 \mathrm{MPa}$. If the pressure which acts on the surface of the tube is smaller than $23.2 \mathrm{MPa}$, no motion will take place. If the pressure is greater than $P_{s}$, the tube begins 


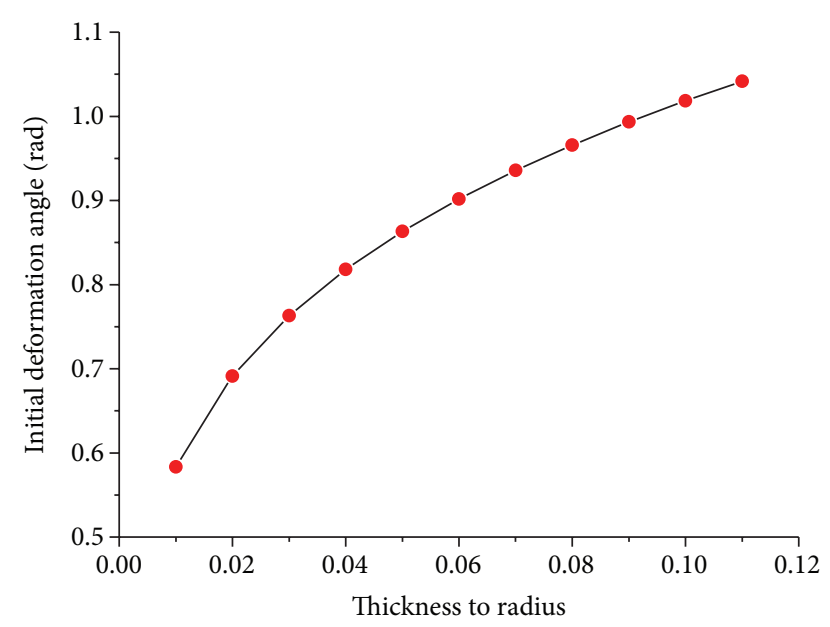

FIgURE 8: The initial deformation angles curves.

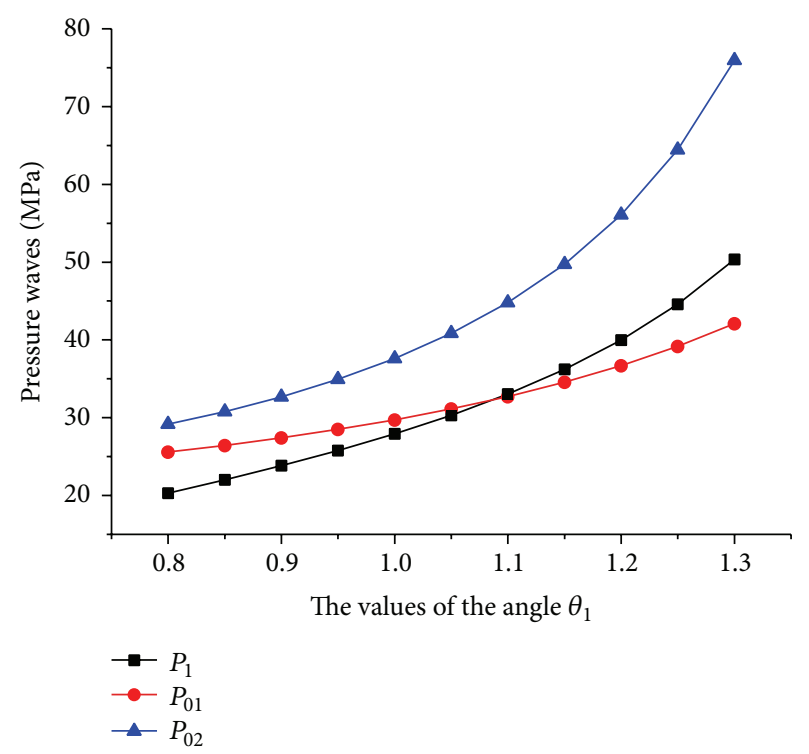

FIGURE 9: Yield conditions for Mechanism I.

to experience accelerated plastic flow. From (13) and (14) we can draw three different curves as shown in Figure 9. As for Mechanism I, the tube model must obey the yield condition of (14), so from Figure 9 we get the condition $P_{1} \leq 32.3 \mathrm{MPa}$. From the above discussion we get a conclusion that Mechanism I is realized in the pressure range $23.2 \mathrm{MPa} \leq P_{1} \leq$ $32.3 \mathrm{MPa}$. The deflection of the tube depending on the pressure wave can be obtained from (11), and the result is shown in Figure 10.

For Mechanism II, the discussion will be a little more complex. Firstly, from (19), we get the coordinate $\theta_{0}$ as a function of wave pressure $P_{1}$, as shown in Figure 11, where $\theta_{0}$ commences from pressure $P_{1}>32.3 \mathrm{MPa}$.

According to the yield condition for Mechanism II, we can also draw three curves of wave pressure from (20), as shown in Figure 12. From Figure 12 and (13) we can get the pressure range for Mechanism II, which is

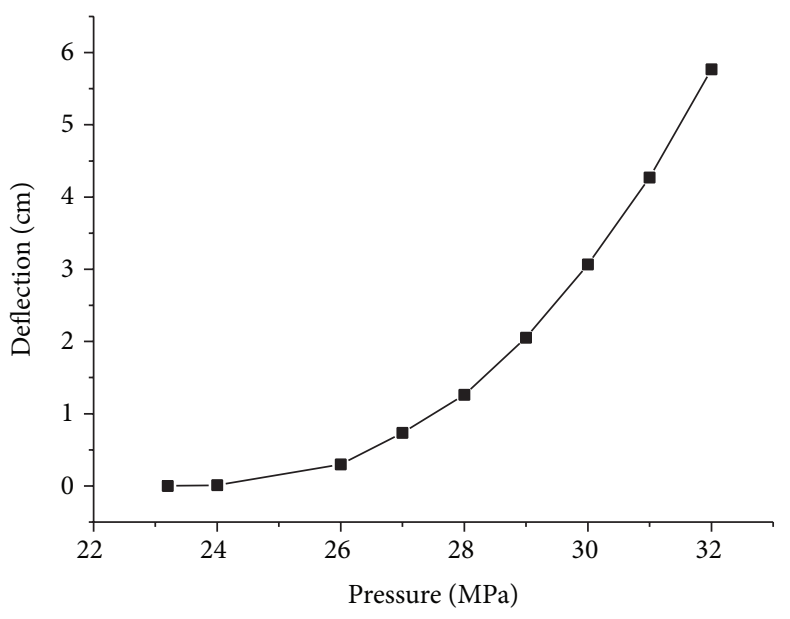

Figure 10: The residual deflection as a function of pressure wave.

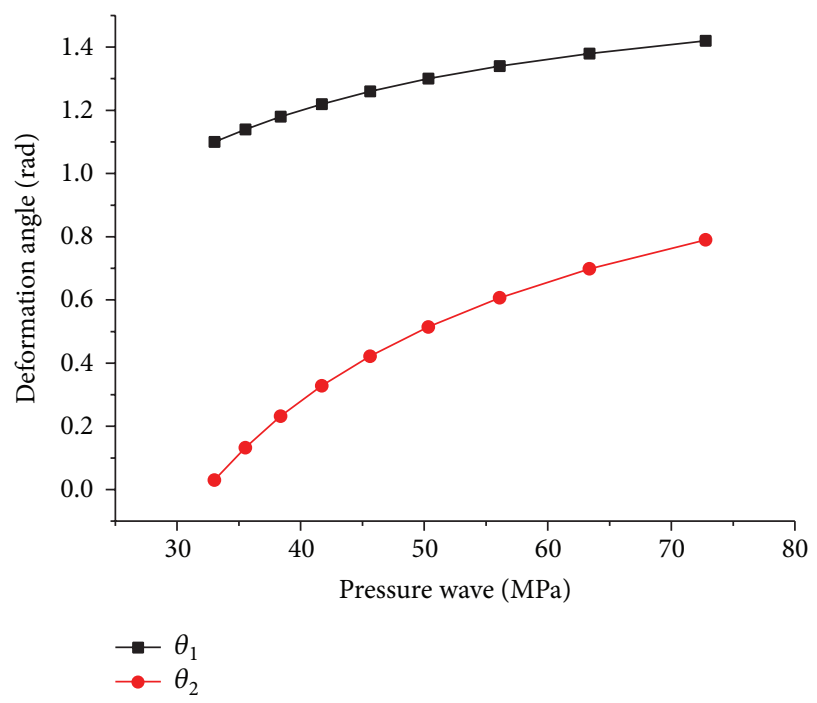

FIgURE 11: The values of the deformation angles as a function of pressure wave.

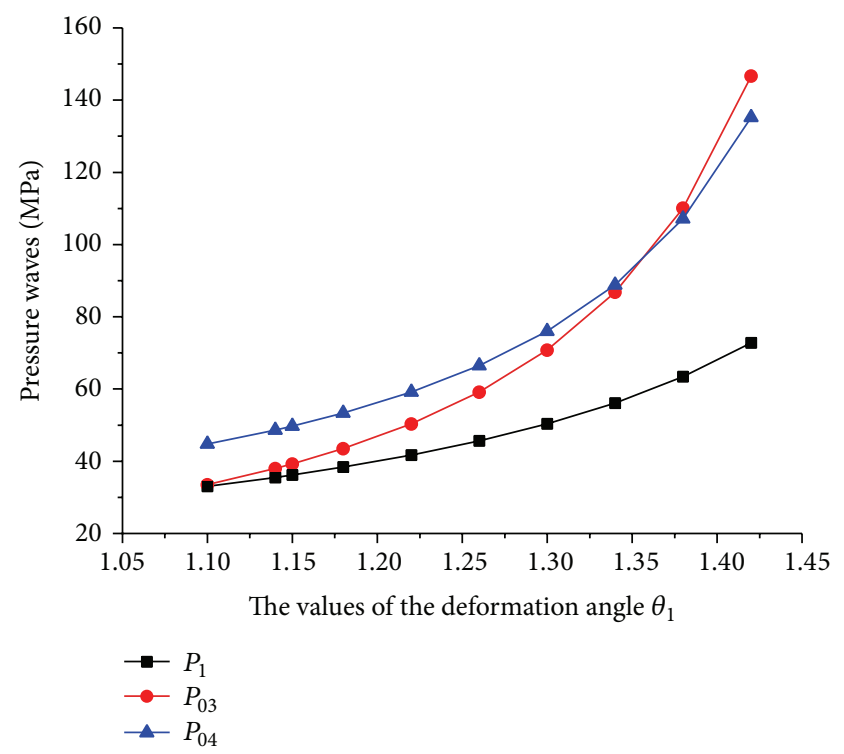

FIgURE 12: Yield conditions for Mechanism II. 
TABLE 2: The result of the experiments.

\begin{tabular}{lccccc}
\hline Run & Charge mass $(\mathrm{g})$ & Tube thickness $(\mathrm{mm})$ & Distance $(\mathrm{cm})$ & Deflection $(\mathrm{cm})$ & Deformation angle \\
\hline 1 & 75 & 2.75 & 8 & 2.4 & 4.2 \\
2 & 2.75 & 6 & 5.7 & 0.74 \\
3 & 75 & 2.75 & 4 & 7.5 & 1.04 \\
4 & 75 & 2.75 & 2 & 6.25 & 1.42 \\
5 & 75 & 2.0 & 8 & 8.6 & 1.39 \\
6 & 75 & 2.0 & 6 & 7.8 & 1.6 \\
7 & 75 & 2.75 & 16 & 14 & 1.5 \\
8 & 200 & 2.75 & Damage \\
\hline
\end{tabular}

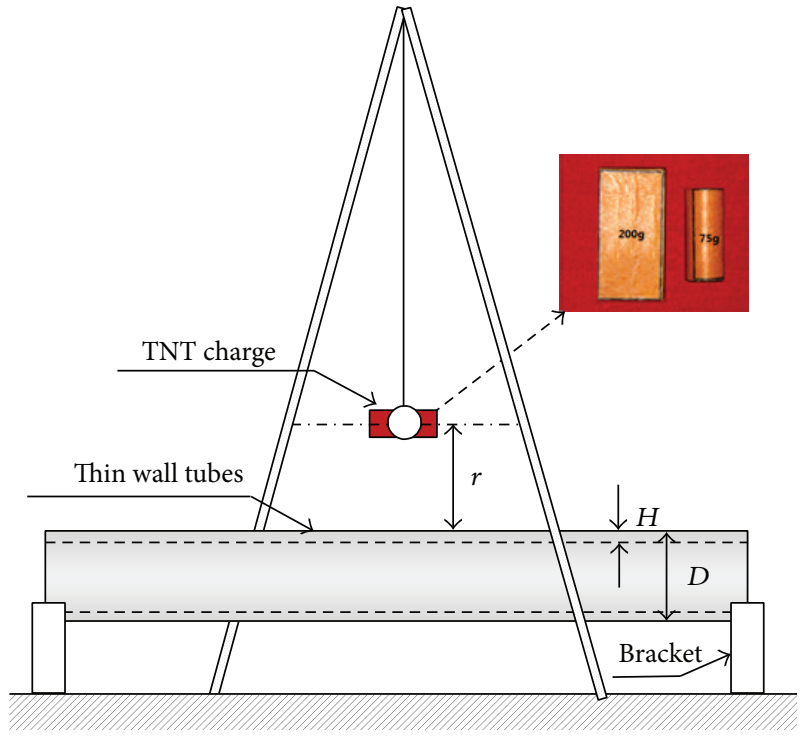

FIGURE 13: Sketches of experiment setup.

32.3 $\mathrm{MPa} \leq P_{1} \leq 164 \mathrm{MPa}$. The residual deflection for Mechanism II can be obtained from (18).

\section{Experimental Phenomena and Results}

In order to get a visual impression of the metal tubes impacted by shock waves, we set up a list of experiments to observe the phenomena. The material of the tubes used in the experiment is Q235 with the length of $1 \mathrm{~m}$ and the outer diameter of $0.1 \mathrm{~m}$. The tubes have two types of thickness, $0.002 \mathrm{~m}$ and $0.00275 \mathrm{~m}$. The setup of the experiment is shown in Figure 13 . The explosives used in the test are $75 \mathrm{~g}$ column TNT charges with a dimension of $30 \mathrm{~mm} \times 70 \mathrm{~mm}$ and $200 \mathrm{~g}$ bulk TNT charge with a dimension of $100 \mathrm{~mm} \times 50 \mathrm{~mm} \times 25 \mathrm{~mm}$, respectively. The explosive is fixed at a certain distance above the tube. The ends of the tube are simply supported.

The typical results of the tube with a thickness of $2.75 \mathrm{~mm}$ are shown in Figures 14 and 15. The explosives used are $75 \mathrm{~g}$ column TNT charges. In Figure 14, results of four different distances between the explosive and the tube surface, which are $8 \mathrm{~cm}, 6 \mathrm{~cm}, 4 \mathrm{~cm}$, and $2 \mathrm{~cm}$, are shown. The deformation of the cross-section in the middle of the tube is shown in

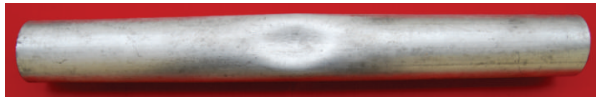

(a) $8 \mathrm{~cm}$

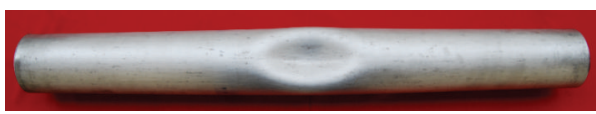

(b) $6 \mathrm{~cm}$

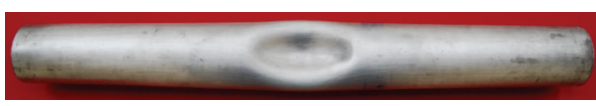

(c) $4 \mathrm{~cm}$

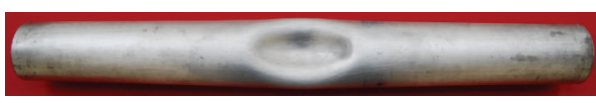

(d) $2 \mathrm{~cm}$

FIGURE 14: $75 \mathrm{~g}$ TNT charges at different distances.

Figure 15. With the distance decreasing from $8 \mathrm{~cm}$ to $2 \mathrm{~cm}$, the deflection becomes larger.

Some of the deflection curves of the cross-section are shown in Figure 16. Figure 16(a) shows the deflection curves of the tube with a thickness of $0.00275 \mathrm{~m}$ and distance of $8 \mathrm{~cm}$. The largest deflection at the midpoint is $2.4 \mathrm{~cm}$, and the angle of deformation $\theta_{s}=0.942$. Figure $15(\mathrm{~b})$ shows the deflection curves of the same tube with a distance of $6 \mathrm{~cm}$. The largest deflection at the midpoint in this situation is $2.4 \mathrm{~cm}$, and the angle of deformation $\theta_{s}=1.04$.

The results of the other experiments are shown in Table 2.

As the distance between the explosive charge and the tube is very small, and the pressure sensor we used at present is too big to use in the experiment, so it is nearly impossible for us to acquire the applied pressure waves acting on the surface of the tube. But the numerical simulation methods can solve the problem quite well. So we carry out the numerical simulations in order to acquire the pressure waves on the tube. The numerical simulations are performed with the commercial finite element code LS-DYNA. Three different material types are involved in the finite element model: the TNT explosive charge, the air, and the metal tube. The Jones-Wilkens-Lee (JWL) equation of state [25] is used to model the action of the TNT explosive charge. The C-J pressure of the TNT explosions $P_{\mathrm{CJ}}=21.0 \mathrm{GPa}$. The mass 


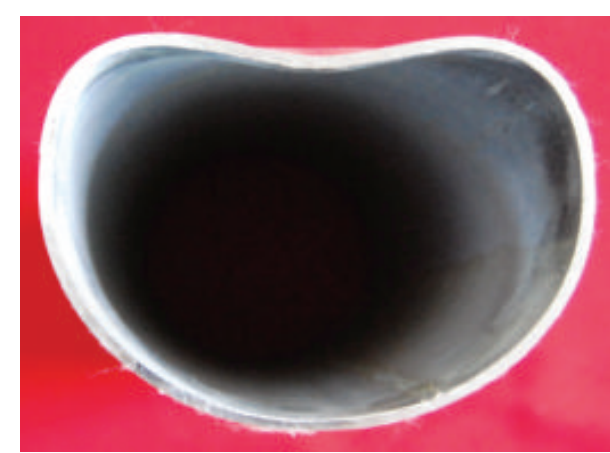

(a) $8 \mathrm{~cm}$

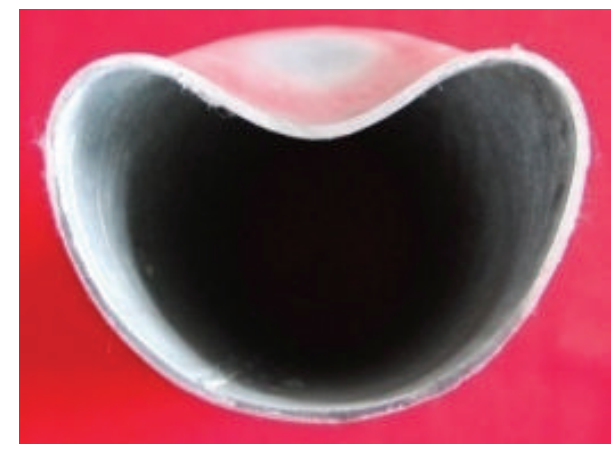

(c) $4 \mathrm{~cm}$

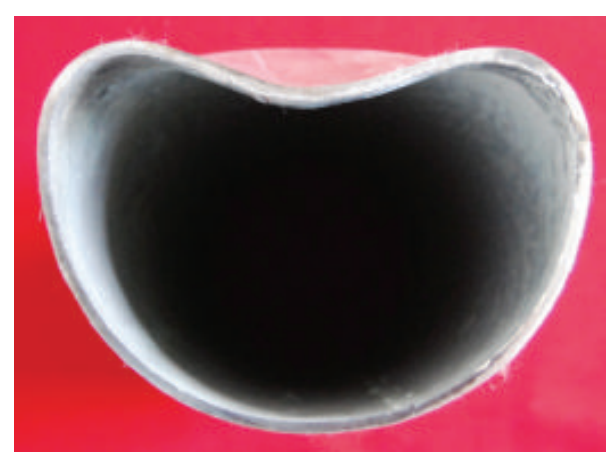

(b) $6 \mathrm{~cm}$

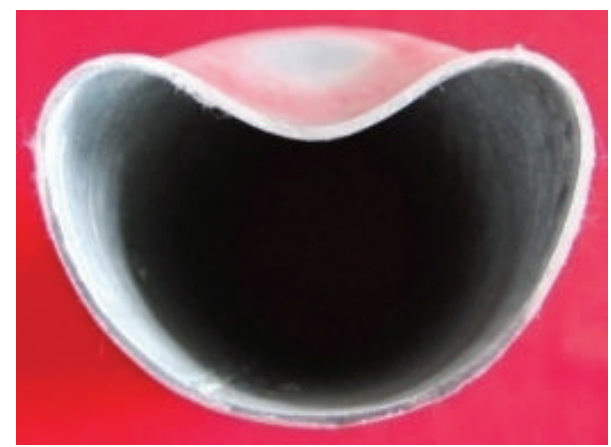

(d) $2 \mathrm{~cm}$

Figure 15: Deformation of the cross-section.

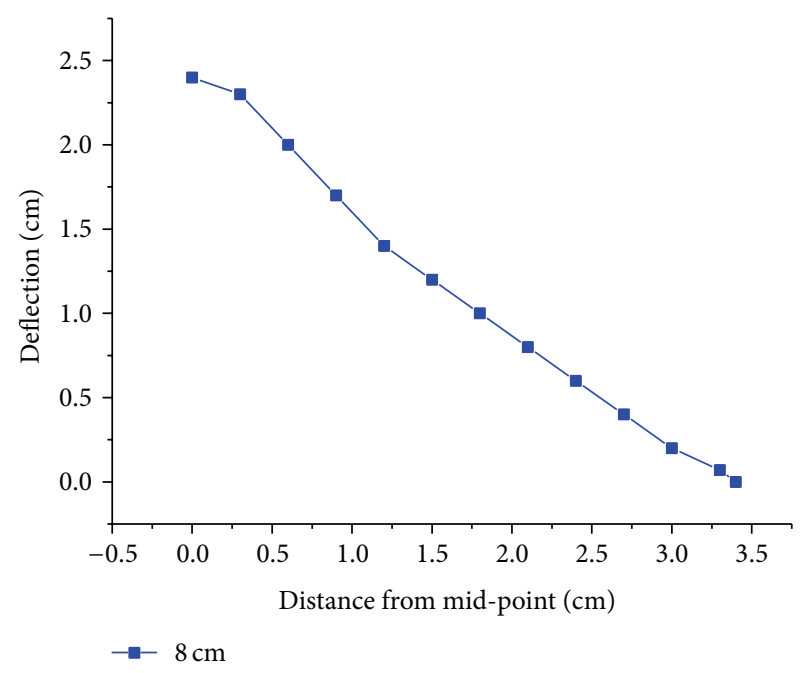

(a)

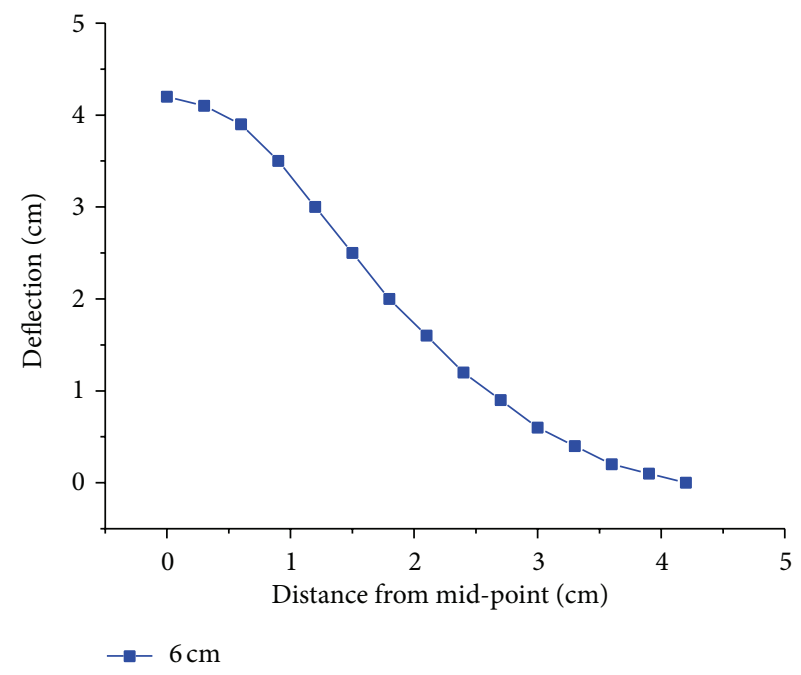

(b)

FIGURE 16: Deflection curves of the tubes subjected to different intensities of the pressure waves.

density $\rho$ and detonation velocity $D$ of TNT explosions are $1610 \mathrm{~kg} / \mathrm{m}^{3}$ and $6930 \mathrm{~m} / \mathrm{s}$, respectively. Material Type 9 of LSDYNA ( ${ }^{*}$ MAT_NULL) is used to model the behavior of the air. Air mass density $\rho_{0}$ and initial internal energy $e_{0}$ are $1.29 \mathrm{~kg} / \mathrm{m}^{3}$ and $0.25 \mathrm{~J} / \mathrm{cm}^{3}$, respectively. The Johnson-Cook (JC) model [26] is used to study the dynamic mechanical behavior of the metal tubes.
Four different geometric parameters are modeled, namely, distances with $2 \mathrm{~cm}, 4 \mathrm{~cm}, 6 \mathrm{~cm}$, and $8 \mathrm{~cm}$. Due to the symmetry of the problem only $1 / 4$ model is used, as shown in Figure 17.

Typical results are presented in Figure 18. From the figure we can get the peak pressures caused by $75 \mathrm{~g}$ TNT charges at the distance of $2 \mathrm{~cm}, 4 \mathrm{~cm}, 6 \mathrm{~cm}$, and $8 \mathrm{~cm}$. Through using the 


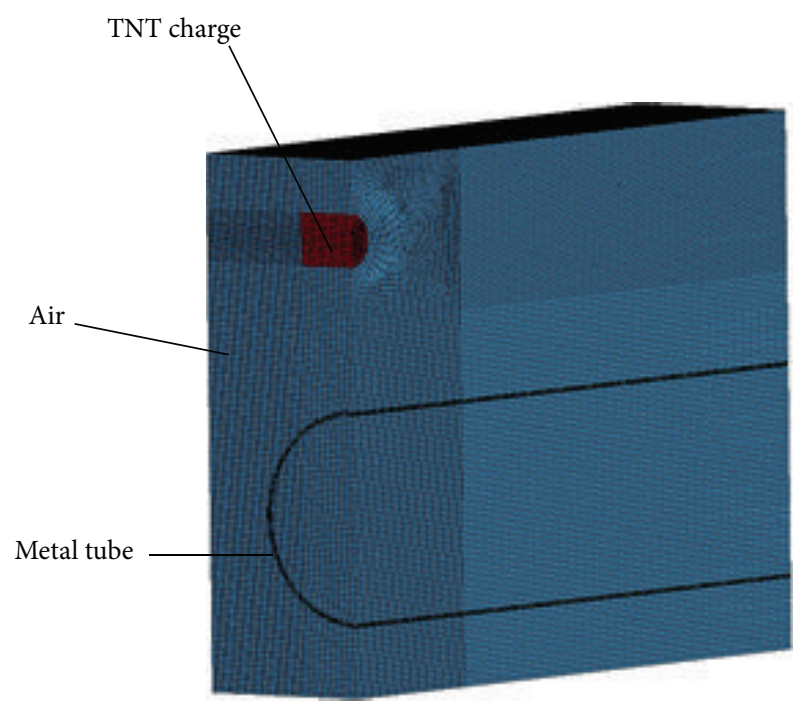

FIGURE 17: Finite element model.

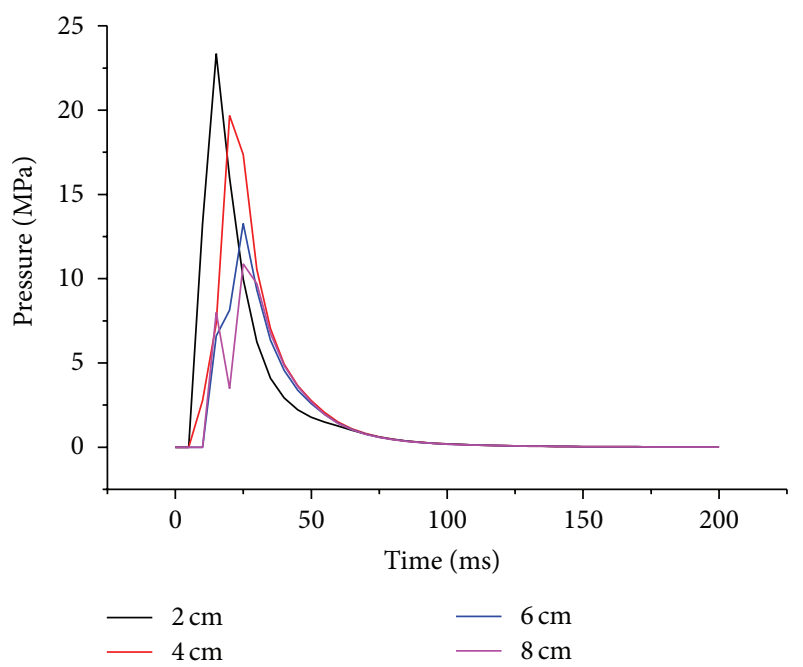

FIGURE 18: Pressure-time curves at different distances.

methods discussed in Sections 3 and 4, we can get the residual deflection.

The pressures are tabulated, along with the theoretical deflections calculated with these pressures, for comparison with the tests. The result is shown in Table 3 .

The comparison shows that the results of numerical simulation agree well with the experiment. Thus, it seems relatively adequate to use this method in the forthcoming optimization study of the metal tubes subjected to the explosion impact loading.

\section{Conclusions}

In this study, an analytical model is presented which predicts the transverse displacement and the deformation angle of the steel circular tubes subjected to a blast load. A series of assumptions is made during the analysis. The form of the load is simplified to be a linearly decaying pulse shape and
TABLE 3: Comparison between numerical simulation and experiment.

\begin{tabular}{lcccc}
\hline $\begin{array}{l}\text { Distance } \\
(\mathrm{cm})\end{array}$ & \multicolumn{2}{c}{$\begin{array}{c}\text { Numerical simulation } \\
P_{0}(\mathrm{MPa})\end{array}$} & $\begin{array}{c}\text { Experiment } \\
\text { Deflection }(\mathrm{cm})\end{array}$ & $\begin{array}{c}\text { Error } \\
\text { Deflection }(\mathrm{cm})\end{array}$ \\
\hline 2 & 22.13 & 7.98 & 7.51 & +6.3 \\
4 & 18.42 & 5.92 & 5.70 & +3.8 \\
6 & 12.26 & 4.02 & 4.22 & -4.7 \\
8 & 10.68 & 2.26 & 2.43 & -6.9 \\
\hline
\end{tabular}

distributed uniformly over the upper semicircle; the tube material is thought to be ideally rigid-plastic; use the simplified Tresca yield domain to describe the plastic flow of the circular tube. On the basis of these assumptions, the following results are obtained.

(1) Two different deformation mechanisms are presented depending on the intensity of the wave: Mechanism I and Mechanism II. The pressure range of each mechanism is calculated depending on the yield condition. The residual deflection can also be obtained from the equation.

(2) A series of experiments are made to observe the phenomena of the circular steel tubes subjected to the blast load. From the experiment we can see that the tubes experience local and global deformations. For the local deformation, the residual deflection of experiment agrees well with that of the numerical calculation.

(3) The method we provided can predict the local deformation of the circular tubes and can be used in the field of security of the oil traveling industry.

\section{Conflict of Interests}

The authors declare that they do not have any commercial or associative interest that represents a conflict of interests in connection with the work submitted.

\section{Acknowledgment}

This research was financially supported by the National Nature Science Foundation of China nos. 11102233 and 51178460 .

\section{References}

[1] P. G. Hodge, "Impact pressure loading of rigid-plastic cylindrical shells," Journal of the Mechanics and Physics of Solids, vol. 3, pp. 176-188, 1955.

[2] N. Jones, "Combined distributed loads on rigid-plastic circular plates with large deflections," International Journal of Solids and Structures, vol. 5, no. 1, pp. 51-64, 1969.

[3] W. J. Stronge, D. Shu, and V. P.-W. Shim, "Dynamic modes of plastic deformation for suddenly loaded, curved beams," International Journal of Impact Engineering, vol. 9, no. 1, pp. 1-18, 1990. 
[4] M. R. Bambach, H. Jama, X. L. Zhao, and R. H. Grzebieta, "Hollow and concrete filled steel hollow sections under transverse impact loads," Engineering Structures, vol. 30, no. 10, pp. 28592870, 2008

[5] C. F. Hung, B. J. Lin, J. J. Hwang-Fuu, and P. Y. Hsu, "Dynamic response of cylindrical shell structures subjected to underwater explosion," Ocean Engineering, vol. 65, pp. 177-191, 2012.

[6] K. Micallef, A. S. Fallah, D. J. Pope, and L. A. Louca, "The dynamic performance of simply-supported rigid-plastic circular steel plates subjected to localised blast loading," International Journal of Mechanical Sciences, vol. 65, no. 1, pp. 177-191, 2012.

[7] J. S. Humphreys, "Plastic deformation of impulsively loaded straight clamped beams," Transactions of the ASME Journal of Applied Mechanics, vol. 32, no. 1, pp. 7-10, 1965.

[8] N. Jones, R. N. Griffin, and R. E. van Duzer, "An experimental study into the dynamic plastic behaviour of wide beams and rectangular plates," International Journal of Mechanical Sciences, vol. 13, no. 8, pp. 721-735, 1971.

[9] P. S. Symonds and N. Jones, "Impulsive loading of fully clamped beams with finite plastic deflections and strain-rate sensitivity," International Journal of Mechanical Sciences, vol. 14, no. 1, pp. 49-69, 1972.

[10] E. H. Lee and P. S. Symonds, "Large plastic deformations of beams under transverse impact," Journal of Applied Mechanics, vol. 19, pp. 308-314, 1952.

[11] P. S. Symonds, "Plastic shear deformations in dynamic load problems," in Engineering Plasticity, pp. 647-664, Cambridge University Press, Cambridge, UK, 1968.

[12] N. Jones, "Influence of strain-hardening and strain-rate sensitivity on the permanent deformation of impulsively loaded rigid-plastic beams," International Journal of Mechanical Sciences, vol. 9, no. 12, pp. 777-796, 1967.

[13] N. Jones, "A theoretical study of the dynamic plastic behavior of beams and plates with finite-deflections," International Journal of Solids and Structures, vol. 7, no. 8, pp. 1007-1029, 1971.

[14] T. Wierzbicki and M. S. Suh, "Indentation of tubes under combined loading," International Journal of Mechanical Sciences, vol. 30, no. 3-4, pp. 229-248, 1988.

[15] A. R. Watson, S. R. Reid, and W. Johnson, "Large deformations of thin-walled circular tubes under transverse loading-III: further experiments on the bending of simply supported tubes," International Journal of Mechanical Sciences, vol. 18, no. 9-10, pp. 501-502, 1976.

[16] A. R. Watson, S. R. Reid, W. Johnson, and S. G. Thomas, "Large deformations of thin-walled circular tubes under transverse loading-II. Experimental study of the crushing of circular tubes by centrally applied opposed wedge-shaped indenters," International Journal of Mechanical Sciences, vol. 18, no. 7-8, pp. 387-IN14, 1976.

[17] N. Jones, S. E. Birch, R. S. Birch, L. Zhu, and M. Brown, "An experimental study on the lateral impact of clamped mild steel pipes," Proceedings of the Institution of Mechanical Engineers, Part E: Journal of Process Mechanical Engineering, vol. 206, pp. 111-127, 1992.

[18] W. Q. Shen and D. W. Shu, "A theoretical analysis on the failure of unpressurized and pressurized pipelines," Proceedings of the Institution of Mechanical Engineers, Part E: Journal of Process Mechanical Engineering, vol. 216, no. 3, pp. 151-165, 2002.

[19] C. S. Ng and W. Q. Shen, "Effect of lateral impact loads on failure of pressurized pipelines supported by foundation," Proceedings of the Institution of Mechanical Engineers, Part E: Journal of
Process Mechanical Engineering, vol. 220, no. 4, pp. 193-206, 2006.

[20] A. S. Fallah and K. Micallef, "Dynamic response of Dyneema ${ }^{\circledR} \mathrm{HB} 26$ plates to localised blast loading," International Journal of Impact Engineering, vol. 73, pp. 91-100, 2014.

[21] Y. P. Zhao, "Suggestion of a new dimensionless number for dynamic plastic response of beams and plates," Archive of Applied Mechanics, vol. 68, no. 7-8, pp. 524-538, 1998.

[22] N. Jones, Structural Impact, Cambridge University Press, Cambridge, UK, 1997.

[23] R. G. Yakupov, "Plastic deformation of a cylindrical shell under the action of a planar explosion wave," Zhurnal Prikladnoi Mekhaniki I Tekhnicheskoi Fiziki, no. 4, pp. 127-132, 1982.

[24] H. Chen, J. Zhou, H. Fan et al., "Dynamic responses of buried arch structure subjected to subsurface localized impulsive loading: experimental study," International Journal of Impact Engineering, vol. 65, pp. 89-101, 2014.

[25] Livermore Software Technology Corporation (LSTC), LSDYNA Keyword User's Manual, Version 960, Livermore, Calif, USA, 2003.

[26] G. R. Johnson and W. H. Cook, "A constitutive model and data for metals subjected to large strain, high strain rates and high temperature," in Proceedings of the 7th International Symposium on Ballistics, pp. 541-548, The Hague, The Netherlands, 1983. 


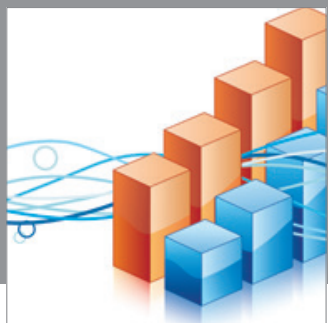

Advances in

Operations Research

mansans

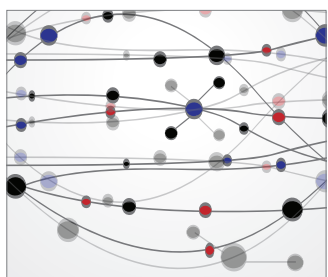

The Scientific World Journal
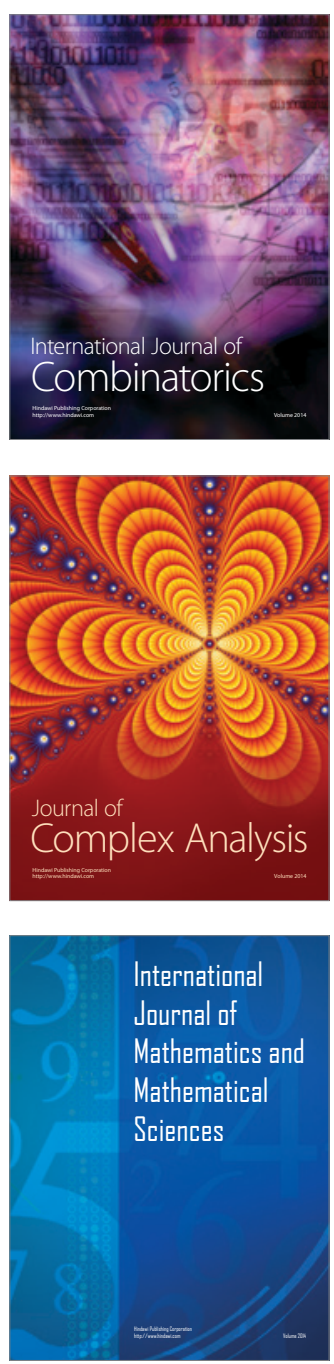
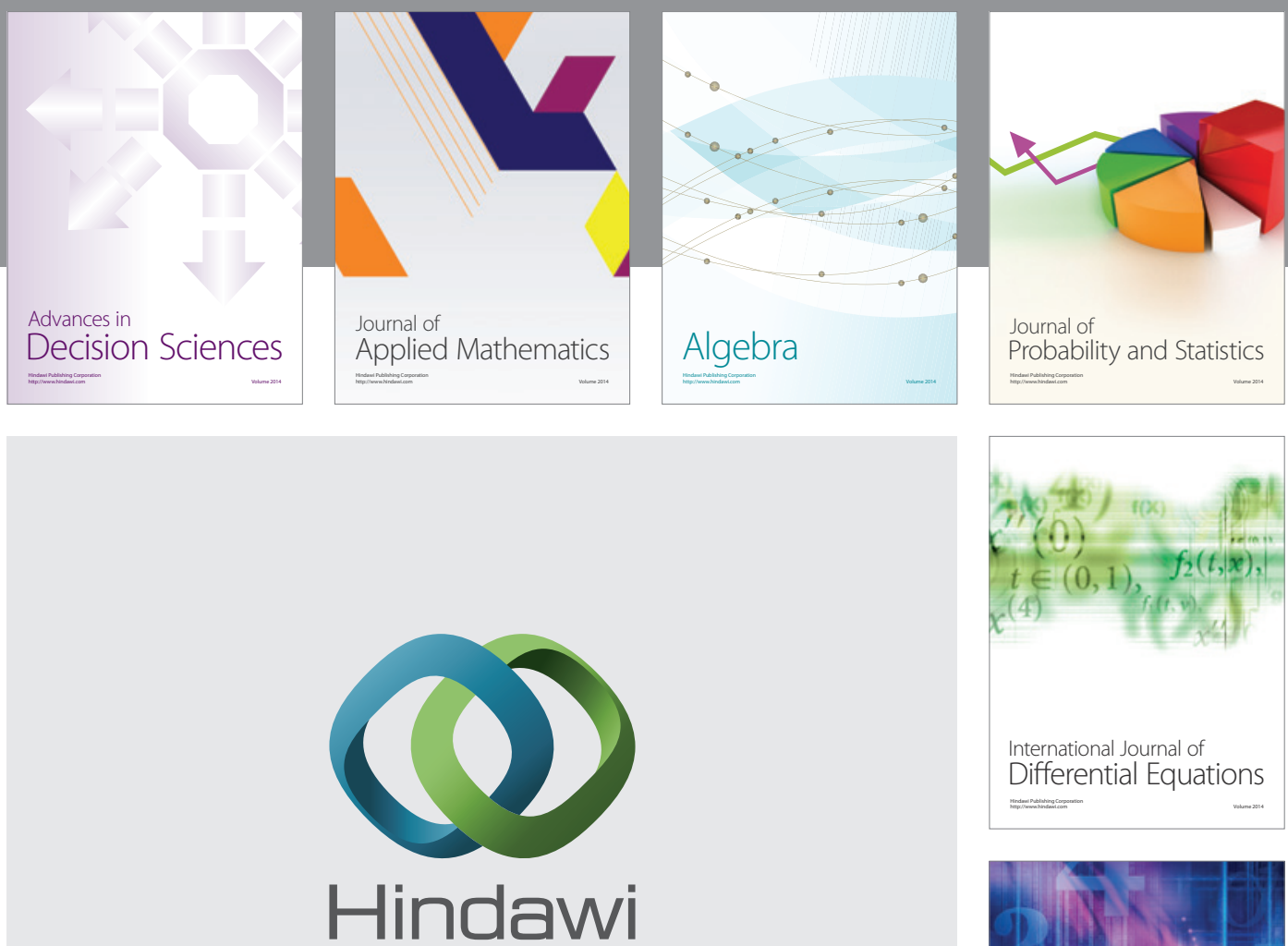

Submit your manuscripts at http://www.hindawi.com
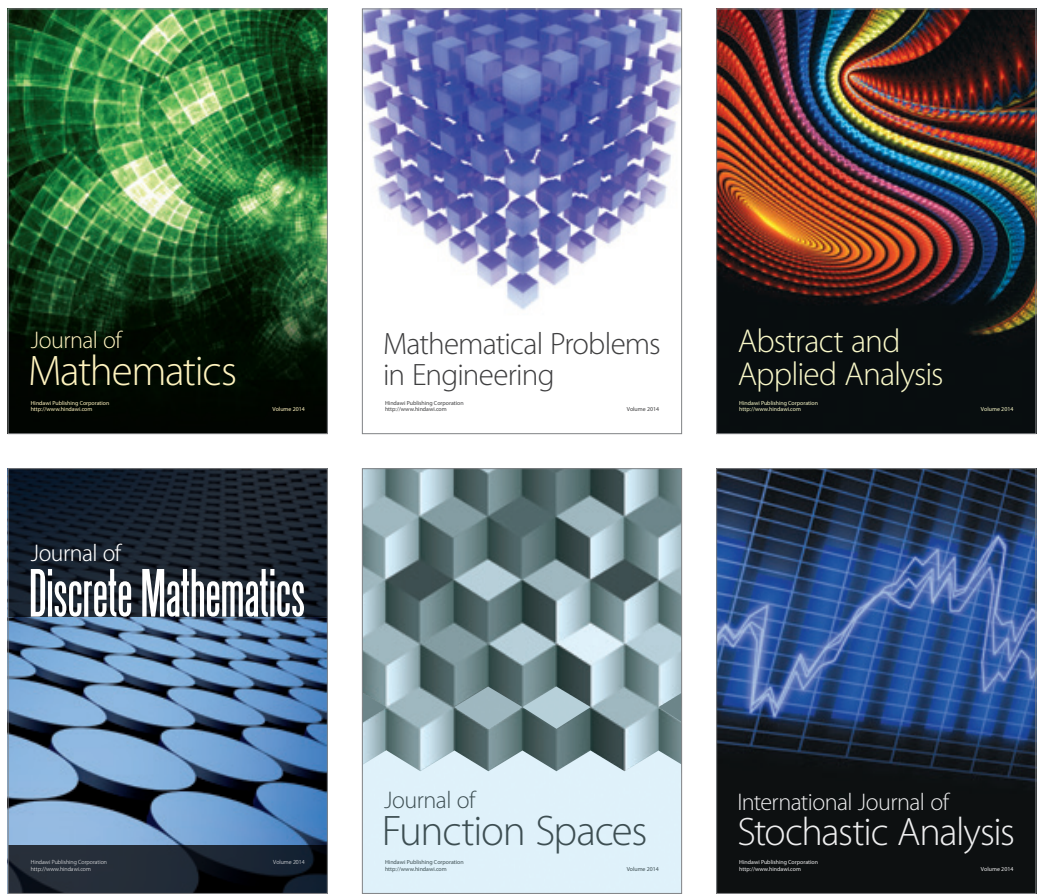

Journal of

Function Spaces

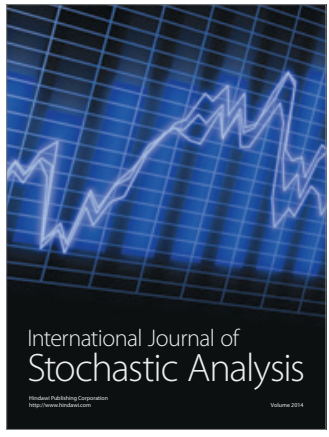

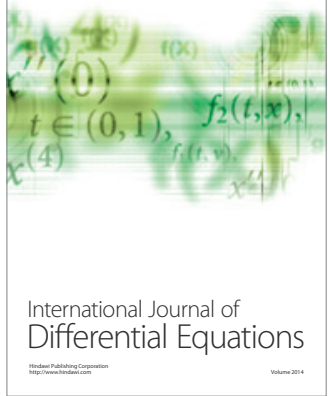
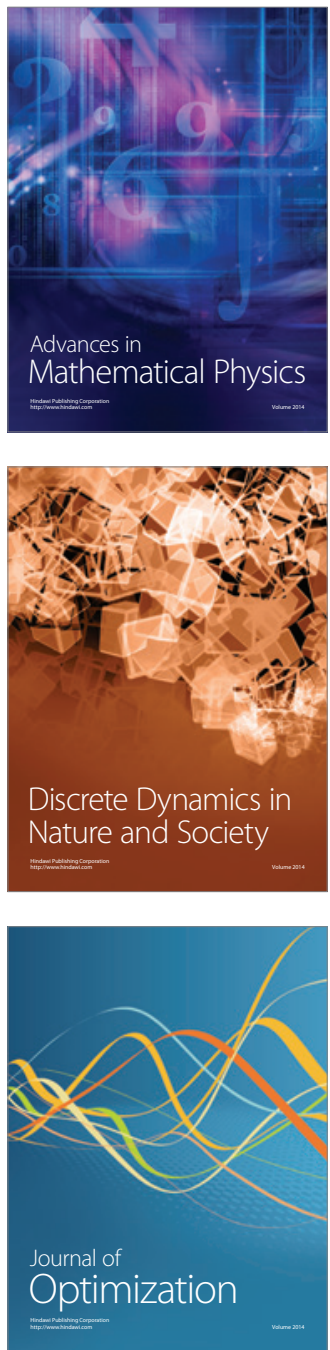